\title{
RESEARCH ON THE USE OF TAGUCHI'S METHOD TO MODEL THE MILLING PROCESS OF SOME METAL MATERIALS
}

\author{
Alina Bianca Pop ${ }^{1}$, Costel Ceocea ${ }^{2}$, Sebastian Emanuel Stan ${ }^{3}$, Aurel Mihail Țîtutu, \\ ${ }^{1}$ SC TECHNOCAD SA, 72, Vasile Alecsandri Street, Baia Mare, Romania \\ ${ }^{2}$ Vasile Alecsandri University of Bacău, 157 Mărăști Street, Bacău, Romania \\ ${ }^{3}$ Land Forces Academy Nicolae Balcescu, Sibiu, Romania \\ ${ }^{4}$ Lucian Blaga University of Sibiu, 10, Victoriei Street, Sibiu, România \\ ${ }_{5}$ The Academy of Romanian Scientists, 54, Splaiul Independenței, Sector 5, Bucharest, Romania \\ E-mails: bianca.bontiu@gmail.com,costelceocea@gmail.com,office.sstan@gmail.com, mihail.titu@ulbsibiu.ro
}

\begin{abstract}
The paper is based on an applied scientific research carried out within a doctoral thesis. It is proposed to use the Taguchi Method in order to model the cutting regime factors to obtain the best quality of the surface machined by the end-milling, considering experimental statistical modelling. The orthogonal matrix, the signal-noise ratio and the variance analysis are used to study the performance conditions in the milling operation of an aluminum workpiece using a standard cutting tool. Three end-milling factors, namely, cutting speed, cutting depth and feed rate, are modelled considering the surface roughness. The tests results obtained are disseminated to illustrate the effectiveness of the analyzed process.
\end{abstract}

Keywords: Taguchi's Method, Cutting Parameters, Surface Roughness, End-Milling, Experimental Statistical Modelling.

\section{Introduction}

The experimental design is one of the most important tools used for modeling and at the same time analyzing the influence that control factors can have on the performance of the production.

In this context, the classical experimental design approach presents a high level of difficulty when it is necessary to carry out a considerable number of experiments, and the number of factors is increasing $[1,2,3]$.

An essential stage in the design of the experiment is the selection of control factors $[4,5,6]$.

Taguchi's method includes an experiment plan aimed at acquiring a data package in a controllable manner, performing the necessary tests and collecting the analysis information to gain data on the behavior of the analyzed process $[7,8,9]$.

In accordance with Taguchi's approach, the quality of a product implies a definition focused on the terms of the loss offered by the product to the company from the moment of delivery to the customer $[10,11,12]$.

In this scientific research, the design of parameters according to Taguchi's methodology is the most important phase and implies the achievement of the objective of determining their optimum values in the cylinder-front milling process in order to reach the lowest surface roughness values for an aluminum alloy, chosen with properties superior to other alloys of this material.

\section{Research Methodology}

\section{Conduct the experiments}

The experimental research will be carried out considering the following aspects:

- Cutting process: end-milling;

- CNC: 3 axis - HAAS VF2;

- Workpiece material: aluminum alloy 7136 .

- Cutting tool: SECO type R217.69-1616.0-092AN, with two indexable cutting inserts XOEX090308FR-E05, H15;

- The cutting process parameters: cutting speed, cutting depth, feed per tooth;

- Direction of research: Ra surface roughness;

- Measuring devices: Portable surface roughness tester - TESA RUGOSURF 20.

\section{Choosing the method}

The research related to this work will be performed with Taguchi method and ANOVA analysis.

\section{The stages of the experimental plan using Taguchi's method}

- The factors identification which are involved in the analyzed process;

- Selecting and defining the parameters to be studied;

- Choosing the levels for each parameter;

- The orthogonal array; 
- Carrying out the research according to the Taguchi experiments plan;

- Data analysis and interpretation;

- Determining the best level of each control parameter.

\section{The objective of the research}

This paper aim is to determine the optimum values of some cutting parameters to increase the performance of the end-milling process, and to obtain a minimum sensitivity to the uncontrollable factors and a surface roughness as small as possible.

\section{Statistical application}

The software application used in the research is Statistica ${ }^{\circledR}$. This application offers the possibility to perform a series of data analyzes, to manage them, to view them as well as a package of procedures for extracting them along with a data variety, predictive modeling, clustering, and classification and exploration techniques.

\section{Design and Analysis of experiments}

A first step in this analysis involves generating the design of experiment. In this case, Taguchi robust design experiments (orthogonal array) was chosen. Experimentation involves determining the effect of 3 factors (table 1): cutting speed, cutting depth and tooth advance, each being tested at 2 levels, with the help of a complete factorial plan, which leads to $2^{3}=$ 8 tests.

Table 1. The adjustment parameters and the values of the related levels

\begin{tabular}{|l|l|l|l|l|}
\hline Abbreviation & Parameter & Parameter name & Value 1 - min & Value 2-max \\
\hline A & Parameter 1 & Cutting speed & $495,00[\mathrm{~m} / \mathrm{min}]$ & $660,00[\mathrm{~m} / \mathrm{min}]$ \\
\hline B & Parameter 2 & Cutting depth & $2[\mathrm{~mm}]$ & $4[\mathrm{~mm}]$ \\
\hline C & Parameter 3 & Feed per tooth & $0,04[\mathrm{~mm} /$ tooth $]$ & $0,14[\mathrm{~mm} /$ tooth $]$ \\
\hline
\end{tabular}

After determining the number of tests required, the next step is to choose an array of experiences.

\section{Choosing an array of experiences}

Starting from the conditions necessary for the realization of an experiment plan, orthogonality is a primary condition in order to be able to calculate the effects of a factor independent of other factors.

According to Taguchi's method, the aim is to make as few experiments as possible by the factors combination using the orthogonal array.

In accordance with Taguchi's method the closest matrix is L8 $\left(2^{7}\right)$, in which the notation of the plan has the following meaning (figure 1):

L8 - means that the array has 8 lines which is equivalent to the plan having 8 experimental determinations;

$2^{7}$ - means 7 columns with 7 digits for two levels;

There are 3 factors with 2 levels each.

$$
\left(\begin{array}{lll}
1 & 1 & 1 \\
1 & 1 & 2 \\
1 & 2 & 1 \\
1 & 2 & 2 \\
2 & 1 & 1 \\
2 & 1 & 2 \\
2 & 2 & 1 \\
2 & 2 & 2
\end{array}\right)
$$

Figure 1: Orthogonal array L8(27) for choosing the parameter values for each experiment

\section{Experiment design analysis (DOE)}

Since it is desired to obtain a roughness of the machined surface (Smaller-the-better), the dependent and independent variables are established, as follows:

- Dependent variables: surface roughness Ra med;

- Independent variables: cutting speed, cutting depth and feed rate.

Table 2 presents the Ra measured values according to the parameters established for the 8 tests performed according to the array in figure 1.

Table 2. The measured values of roughness Ra according to the parameters established for the 8 tests

\begin{tabular}{|l|l|l|l|l|l|l|l|}
\hline \multirow{2}{*}{$\begin{array}{c}\text { Trial } \\
\text { number }\end{array}$} & \multicolumn{4}{l}{ Adjustment parameters } & \multicolumn{2}{l|}{ Ra results $[\mu \mathrm{m}]$} \\
\cline { 2 - 8 } & $\mathrm{v}[\mathrm{m} / \mathrm{min}]$ & $\mathrm{ap}[\mathrm{mm}]$ & fz $[\mathrm{mm} /$ tooth] & Ra1 & Ra2 & Ra3 & Ra med \\
\hline 1 & 495 & 2 & 0,04 & 0,083 & 0,063 & 0,063 & 0,070 \\
\hline 2 & 495 & 2 & 0,14 & 0,173 & 0,168 & 0,124 & 0,155 \\
\hline 3 & 495 & 4 & 0,04 & 0,44 & 0,341 & 0,456 & 0,412 \\
\hline 4 & 495 & 4 & 0,14 & 0,115 & 0,11 & 0,098 & 0,108 \\
\hline 5 & 660 & 4 & 0,04 & 0,073 & 0,064 & 0,075 & 0,071 \\
\hline 6 & 660 & 4 & 0,14 & 0,394 & 0,385 & 0,247 & 0,342 \\
\hline 7 & 660 & 2 & 0,04 & 0,079 & 0,055 & 0,088 & 0,074 \\
\hline 8 & 660 & 2 & 0,14 & 0,12 & 0,095 & 0,181 & 0,132 \\
\hline
\end{tabular}


Using the statistical application, the averages were calculated (for Eta, the S/N signal-noise ratio) for each level for each parameter and the parameter estimates - that is, the average deviations of the respective factor level from the total average $(\mu)$.
Considering that it is desired to obtain a minimum roughness of the end-milled surface, in this sense it is necessary that the $\mathrm{S} / \mathrm{N}$ ratios be maximized.

Figure 2 shows a summary of these averages, in a graphical form.

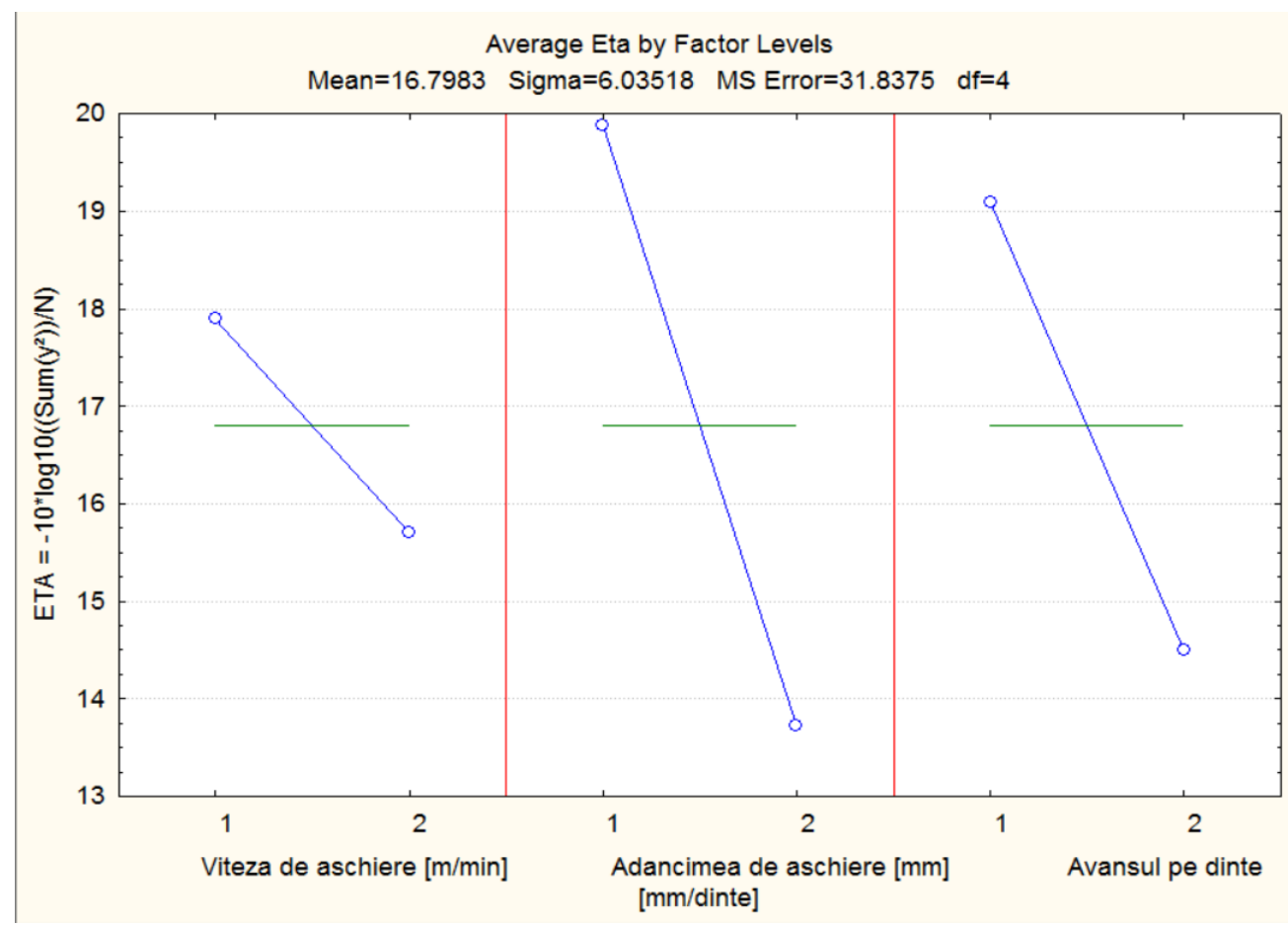

Figure 2: Average Eta by Factor Levels

In this graph, the best levels for each factor can be easily identified, that is, those that lead to obtain the highest $\mathrm{S} / \mathrm{N}$ ratio. Specifically, for all the cutting factors in this study, the highest $\mathrm{S} / \mathrm{N}$ ratio appears at level 2.

Eta expresses the intensity of the connection between a nominal variable and an ordinal or scalar variable.

\section{ANOVA}

The following is the ANOVA analysis which is closely related to the obtained results, as the standard errors reported depend on the interpretations made previously.

Table 3 summarizes the results obtained from this analysis.

Table 3. Analysis of Variance - ANOVA

\begin{tabular}{|l|l|l|l|l|l|}
\hline Effect & SS & df & MS & F & p \\
\hline (1)Cutting speed [m/min] & 9.6475 & 1 & 9.64752 & 0.303024 & 0.611289 \\
\hline (2)Cutting depth [mm] & 75.6719 & 1 & 75.67191 & 2.376816 & 0.198006 \\
\hline (3)Feed per tooth [mm/tooth] & 42.2941 & 1 & 42.29414 & 1.328437 & 0.313276 \\
\hline Residual & 127.3501 & 4 & 31.83751 & & \\
\hline
\end{tabular}

In table 3 the symbols represent:

- SS - sum of squares;

- Df - Degrees of freedom;

- MS - Average of squares;

- $F$ is the value of the Fisher (Fratio) test coefficient;

- $\mathrm{P}$ - Each ratio $\mathrm{F}$ is calculated as the ratio of two MS values. Each of these MS values has an appropriate number of degrees of freedom. Thus the ratio $\mathrm{F}$ is associated with a number of degrees of freedom for the numerator and another for the denominator;
- Residual - Typically, to obtain a more stable estimate of error variation, small and insignificant effects are combined within the error term. Even if this procedure exploits the chance (and the resulting $\mathrm{p}$ values are suspect), it produces several stable predictions later.

\section{Perform optimization of the equation state}

The combination of the insignificant effects in the error term exploits its occurrence and, significant factors can be identified. 
One way to "verify" the results obtained is by first predicting Eta under optimal conditions, based on the factors identified as significant, that is, in our case the cutting depth having the greatest influence.

Then we can run a verification experiment, that is, a few runs using these real settings. If significant differences occur between predicted and observed values, then factors that were unimportant, or unexpected interactions between factors, were erroneously included.

The Signal / Noise ratio, used to measure the results, simultaneously takes into account the average of the relative measurements of each test on the one hand, and their dispersion, the average of the standard deviations, on the other. Therefore, the higher the algebraic value of the Signal / Noise ratio, the lower the recorded loss and the better the cutting process performance.

By default, all factors are set to their optimal level, that is, to the levels that produce the highest $\mathrm{S}$ / $\mathrm{N}$ ratio.

Table 4 presents the signal-to-noise ratio results obtained under optimal conditions.

Table 4. Expected S/N Ratio under the Optimum Conditions

\begin{tabular}{|l|l|l|l|}
\hline Effect & Level & Effect size & Standard error \\
\hline (1)Cutting speed [m/min] & 1 & 1.09815 & 2.821237 \\
\hline (2)Cutting depth [mm] & 1 & 3.07555 & 2.821237 \\
\hline (3)Feed per tooth [mm/tooth] & 1 & 2.29930 & 2.821237 \\
\hline Expected S/N & & 23.27127 & \\
\hline
\end{tabular}

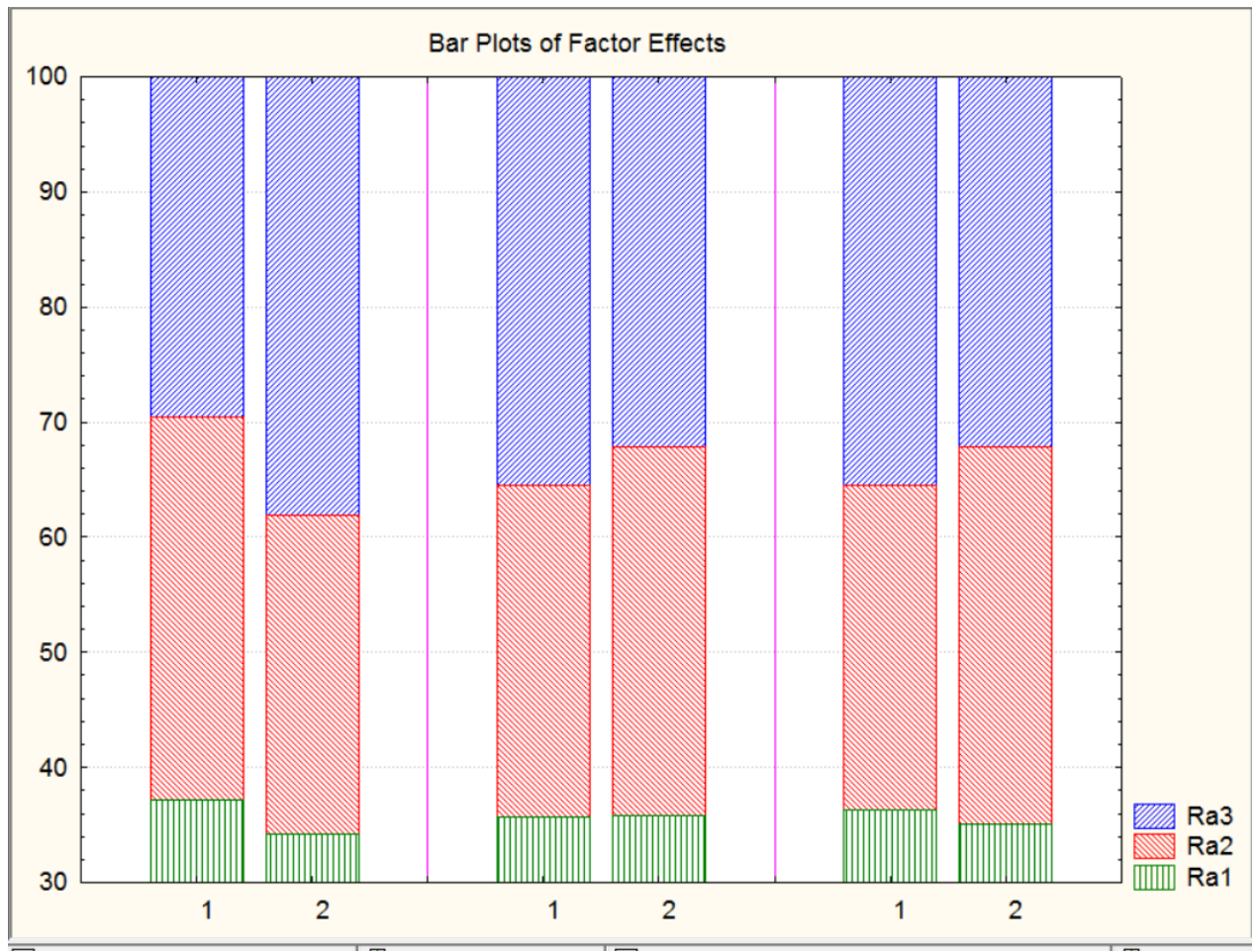

Figure 3: Bar Plots of Factor Effects

The conclusion is that factors and their levels should be reviewed so that no meaningful interactions remain. In this respect, traditional factorial designs on two levels (with sufficient resolution) can be used to detect the interactions in the research data.

In more detail, the results obtained can be viewed through bar graphs with cumulative proportions (figure 3). In this graph, the relative frequencies (proportions) of each category (Ra1, Ra2, Ra3) for each level of each factor are displayed in stacked columns. For example, for the first factor (cutting speed), we can immediately recognize that the largest coverage area appears below level 1.

This information for this factor can also be displayed by a linear graph with the cumulative proportions between categories (figure 4). 


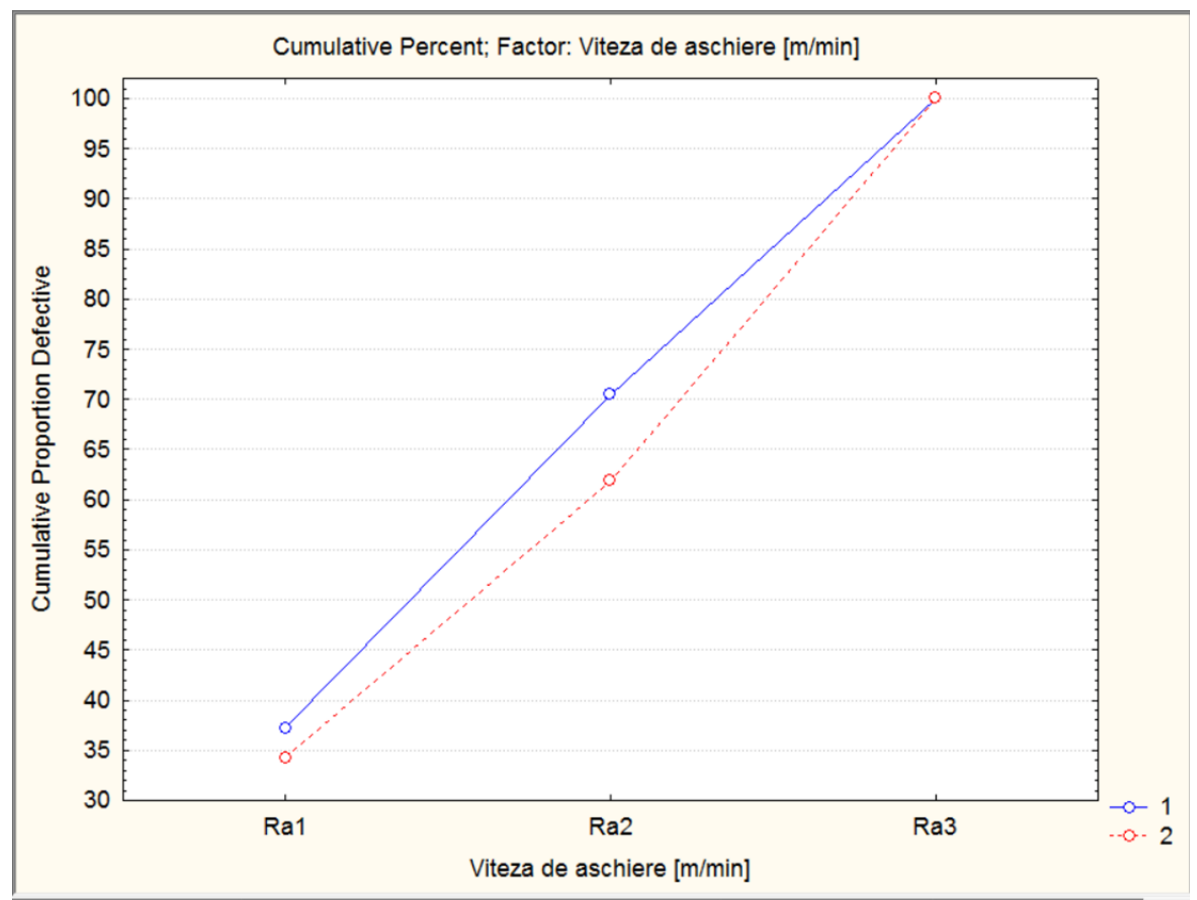

Figure 4: Cumulative Percent - factor - cutting speed [m/min]

As shown in the illustration above, the line indicating the cumulative proportion at which the highest roughness is recorded is the one for level 1.
Finally, following the optimization, the results presented in table 5 were obtained.

Table 5. Effect sizes and expected S/N Ratio

\begin{tabular}{|l|l|l|l|}
\hline Effect & Level & $\mathrm{Ra}_{1}$ & $\mathrm{Ra}_{2}$ \\
\hline (1)Cutting speed [m/min] & 1 & -2.27565 & 3.772794 \\
\hline (2)Cutting depth [mm] & 2 & -2.54581 & 3.243579 \\
\hline (3)Feed per tooth [mm/tooth] & 2 & -2.66328 & 3.236961 \\
\hline Mean S/N & & -2.54998 & 2.910702 \\
\hline Expected S/N & & -2.38378 & 4.431931 \\
\hline
\end{tabular}

\section{Conclusions}

In this paper, the subject of the surface quality during milling of an aluminum alloy was debated.

This theme was chosen due to the fact that in the cutting process industry and in the manufacturing industries, surface finishing and product strength are essential in determining quality.

The best surface finish also ensures a high quality of the final product.

The effect and optimization of the cutting parameters on the surface roughness was investigated using the Taguchi and ANOVA methods.

Following the optimization of the equation of state it is found that in order to obtain the best quality of the processed surface and therefore a small roughness, it is necessary that the cutting speed be as high as possible and the cutting depth and the advance on the tooth, small.

\section{References}

[1] Sahithia V.V.D., Malayadrib T., Srilathac N., Optimization Of Turning Parameters On Surface Roughness Based On Taguchi Technique, Materials Today: Proceedings 18 (2019) 36573666, www.materialstoday.com/proceedings, 2019.

[2] I. Asilturk, H. Akkus, Determining the effect of cutting parameters on surface roughness in hard turning using the Taguchi method, Measurement 44 (2011) 1697-1704.

[3] S.S. Mahapatra, A. Patnaik, Study on mechanical and erosion wear behavior of hybrid composites using Taguchi experimental design, Mater. Des. 30 (2009) 2791-2801.

[4] A. Uysal, M. Altan, E. Altan, Effects of cutting parameters on tool wear in drilling of polymer composite by Taguchi method, Int. J. Adv. Manuf. Technol. 58 (9-12) (2012) 915-921. 
[5] P. Ross, Taguchi Techniques for Quality Engineering: Loss Function, Orthogonal Experiments, Parameter and Tolerance Design, McGraw-Hill, New York, 1998.

[6] G.Taguchi, S. Konishi, Taguchi Methods, Orthogonal Arrays and Linear Graphs, Tool for Quality Engineering, American Supplier Institute, Dearborn, 1987, pp. 35-38.

[7] J.A. Ghani, I.A. Choudhury, H.H. Hassan, Application of Taguchi method in the optimization of end milling parameters, J. Mater. Process. Technol. 145 (2004) 84-92.

[8] Alagarsamy, S. V., P. Raveendran, V. S. Arockia, and V. Tamil. "Optimization of Machining Parameters for Turning of Aluminium Alloy 5 Using Taguchi Method." International Research Journal of Engineering and Technology 3, no. 1 (2016): 316-322.

[9] Pop AB and Țîțu MA, The experimental research strategy of the endmilled aluminum alloys MATEC Web of Conferences 112 01010, 2017.
[10] Sonowal, Dharindom, Dhrupad Sarma, ParimalBakulBarua, and Thuleswar Nath. Taguchi Optimization of Cutting Parameters in Turning AISI 1020 MS with M2 HSS Tool. In IOP Conference Series: Materials Science and Engineering, vol. 225, no. 1, p. 012186. IOP Publishing, 2017.

[11] Țîţu MA, Pop AB, 2017.Using regression analysis method to model and optimize the quality of chip-removing processed metal surfaces MATEC Web of Conferences 112 01009.

[12] Uysal A, Altan M, Altan E, Effects of cutting parameters ontool wear in drilling of polymer composite by Taguchi method, Int. J. Adv. Manuf. Technol. 58 (9-12) 915-921, 2012.

[13] www.donis.ro. accessed at:03.05.2012 